\title{
One Pot Microwave Irradiation Synthesis of Spherical and Nanotube Titanates Incorporated Reduced Graphene for Efficient Hydrogen Production Photo-Electrocatalytically
}

Mohamed Mohamed ( $\nabla$ mohamed.mokhtar@fsc.bu.edu.eg )

Benha University https://orcid.org/0000-0001-8460-0692

Mahmoud M. Hessien

Taif University

Mohamed M. Ibrahim

Taif University

\section{Research Article}

Keywords: TNT-GO hybrid, Microwave illumination, H2 production, Photocatalysis, Water splitting

Posted Date: July 26th, 2021

DOl: https://doi.org/10.21203/rs.3.rs-746086/v1

License: (c) (1) This work is licensed under a Creative Commons Attribution 4.0 International License. Read Full License

Version of Record: A version of this preprint was published at Journal of Inorganic and Organometallic Polymers and Materials on September 19th, 2021. See the published version at https://doi.org/10.1007/s10904-021-02098-8. 


\section{Abstract}

Nanosphere and nanotube titanates (TNT) amalgamated with different graphene oxide (GO) ratios synthesized by one pot microwave irradiation route have presented excellent potential towards hydrogen production photoelectrochemically under solar irradiation. The hybrid nanospherical array of the 50TNT$50 \mathrm{GO}$ photocatalyst showed a current density equal $9.2 \mathrm{~mA} \mathrm{~cm}^{-2}$ at a bias of $0.20 \mathrm{~V}$ vs. RHE exceeding those of the nanotubes 30TNT-70GO $\left(4.0 \mathrm{~mA} \mathrm{~cm}^{-2}\right.$ at $\left.0.38 \mathrm{~V}\right)$ and $10 \mathrm{TNT}-90 \mathrm{GO}\left(3.7 \mathrm{~mA} \mathrm{~cm}^{-2}\right.$ at $\left.0.4 \mathrm{~V}\right)$. The former electrode also exhibits small Tafel slope value $\left(40 \mathrm{mV} \mathrm{dec}^{-1}\right)$, decreased particle diameter (7 $\mathrm{nm})$, decreased band gap (2.6 eV) and high rate of charges transfer. The hybrid structure elucidation carried out using TEM-SAED, XRD, $\mathrm{N}_{2}$ adsorption, UV-Vis, FTIR and PL techniques approved the interfacial interaction between TNT and GO(RGO) networks that was responsible for the high quantum yield, delay of charges recombination beside the increase in the pore volume.

\section{Introduction}

As a result of recognizing the characteristics of titanate nanotubes that combine those of the traditional $\mathrm{TiO}_{2}$ nanoparticles with the properties of the 1D layered titanates, many applications have been disclosed [1-3]. On the other hand, many approaches have been presented for improving the $\mathrm{TiO}_{2}$ nanotubes photoactivity to be sensitive towards visible light irradiation including nonmetal doping, noble metals doping, as well as incorporation with dyes and polymers [4-7]. However, their limited wide scale applicability were mainly relied on the electron-hole pair recombination, high price, and the feasible split-up.

The established routes for synthesizing $\mathrm{TiO}_{2}$ nanotubes were alkaline hydrothermal, template assisted, and anodic oxidation. However, they suffer morphology control drawback beside declining their properties during applications [8]. Thus, to tackle the mentioned shortcoming and to improve the properties of titanate structure, a modification with graphene has been proposed [9]. Graphene incorporation is an emerging approach because of its large surface area, optical transmittance, and electronic conductivity [10-12]. However, the way of dispersing graphene into titanates is the most important issue. Many routes have been applied such as hydrothermal and soft chemical approaches where the incorporation of GO is primarily used. Indeed, graphene is merged with titanates after the $\mathrm{GO}$ reduction that used to be accomplished via using applied chemical constituents, thermal and microwave treatment routes [13]. This indeed reduces the heterojunction expected to be formed between the nanotubes and graphene and thus produces weak or deficient interfaces. Thus, we tried to use a facile efficient method to boost the water splitting slow kinetics via building up an efficient interface capable of transferring electrons via employing a simple microwave irradiation approach. This is to excellently improve the charge separation/transportation courses and rather facilitate the electrolyte diffusion. Thus, we have synthesized the hybrid $\mathrm{TiO}_{2}$ nanotube-graphene that unveiled an effective visible light harvesting via executing large wavelength range beside facile PEC surface reaction. Consequently, the photocatalytic activities of the $\mathrm{TiO}_{2}$ nanotube-graphene hybrids synthesized by one step microwave route are assessed using hydrogen generation via water splitting. This photoelectrochemical reaction is carried out for sake 
of designing, developing and optimizing a low priced electrocatalyst with a noble metal free and high stability for an efficient water reduction.

\section{Experimental}

\section{Synthesis of graphene oxide (GO) nano-layers}

Graphene oxide nanolayers were fabricated from natural graphite (Adwic Company, Egypt) via applying a modified Hummers' method, subsequent Mohamed et al. [2] procedure.

\section{Synthesis of graphene oxide modified $\mathrm{TiO}_{2}$ nanotube}

The microwave-irradiation route was exploited to synthesize sodium titanate nanotubes. A digester CEM type operated at a power equal $450 \mathrm{~W}$ was used. A $1.0 \mathrm{~g}$ of $\mathrm{TiO}_{2}$ - powder (Degussa) was added to $10 \mathrm{~mol}$ $\mathrm{L}^{-1} \mathrm{NaOH}$ so as to achieve a suspension volume of $60 \mathrm{~mL}$. The synthesis condition was fixed at $150{ }^{\circ} \mathrm{C}$ for $1 \mathrm{~h}$. The obtained suspension was filtered, washed with $0.1 \mathrm{M} \mathrm{HCl}$ several times then dried at $100{ }^{\circ} \mathrm{C}$. For $\mathrm{GO}$ modified titanates samples, definite amounts of $\mathrm{GO}$ to give various weight percentage ratios were immersed into the $\mathrm{TiO}_{2}$ Degussa followed by $\mathrm{NaOH}$ addition and then placed in the closed Teflon container to be treated as above except extending the time into $2 \mathrm{~h}$ to accomplish reduction of GO.

\section{Photo- and electro-chemical measurements}

The photo-current study was performed using a workstation (CHI 660B) containing three-electrode design with X GO-Y TNT electrodes (of area $1.0 \mathrm{~cm}^{2}$ ) as working electrodes. The carbon electrode and reversible hydrogen electrode (RHE) were respectively worked as counter and reference electrodes, and $1.0 \mathrm{M} \mathrm{KOH}$ was utilized as an electrolyte. The carbon counter electrode of good adhesion was synthesized following the procedure of the Q. Meng et al. [13]. The working electrode was prepared using a paste of the X GOY TNT hybrid using $1.0 \mathrm{~mL}$ of the Triton X-100 on the FTO conducting glass (resistance $19 \mathrm{~W} \mathrm{~cm}^{-1}$ ). Impedance spectroscopy (EIS) justified using Kramers-Kronig transformation was verified with an ac disconcertion indicator of $5 \mathrm{mV}$ in the frequency limit of $0.1 \mathrm{~Hz}-100 \mathrm{kHz}$, at a bias of $0.3 \mathrm{~V}$. A $150 \mathrm{~W} \mathrm{Xe}$ lamp (of intensity equal $3.5 \mathrm{~mW} \mathrm{~cm}^{-2}$ ) attached with a UV drop filter ( $>400 \mathrm{~nm}$ ) was exploited as the visible-light supply. The HER exchange currents determined via the cathodic scans of sweep voltammetry (LSV, in the potential window of 0.2-2.0 V and at scan rate of $50 \mathrm{mV} \mathrm{s}^{-1}$ ) and Tafel slopes were also measured in $1.0 \mathrm{M} \mathrm{KOH}$ electrolyte together with the commercial $20 \% \mathrm{Pt} / \mathrm{C}$ for comparative purposes. Transient photocurrent was determined on the same potentiostat at zero bias voltage versus RHE utilizing the referred light source.

\section{Characterization techniques}

The morphology of the samples was measured using both transmission electron microscope (TEM, S$4700)$ and selected area electron diffraction (SAED) technique. The X-ray diffraction (XRD) patterns were conducted on a PANalytical PRO construction with Cu Ka radiation ( $k=1.54056 \AA$ A) controlled at $40 \mathrm{kV}$ 
and $30 \mathrm{~mA}$. The UV-Vis diffuse reflectance spectra were accomplished on a Shimadzu UV-3150, spectrophotometer. The FT-IR spectra were confirmed on a Nicolet Magna-550 spectrometer. The surface area, pore volume and pore radius of the samples were quantified via adsorption of the $\mathrm{N}_{2}$ gas at $-196{ }^{\circ} \mathrm{C}$ using Micromeritics 3020 , subsequent outgassing at $120^{\circ} \mathrm{C}$. The Photoluminescence spectra were carried out using FLS980, Edinburgh Instruments Ltd. with an incited wavelength of $330 \mathrm{~nm}$.

\section{Results And Discussion}

\section{Bulk, morphology, vibration and optical characteristics}

The XRD results of synthesized catalysts consisting of GO and x TNT-y GO are illustrated in Fig.1. The GO pattern shows main peaks at $2 q=10.4^{\circ}(001)$ and $43.5^{\circ}(102)$ with a small broad peak at $20.3^{\circ}$ ascribed to the presence of reduced graphenes (RG) at a minor ratio equivalent to $15 \%$ of the $\mathrm{GO}$. In the 50TNT-50GO pattern, pronounced peaks at $2 q=25^{\circ}(101), 38.08^{\circ}(004), 48.32^{\circ}(200), 54.88^{\circ}(105), 63.36^{\circ}$ (204) are distinguished characterizing the anatase $\mathrm{TiO}_{2}$ structure (anatase, JCPDS: 99-0008) together with a tail peak positioned at $2 q=5^{\circ}(200)$ describes the hydrogen titanate nanotube [14]. In the latter pattern, GO peaks are totally disappeared toward the construction of the RG. However, the RG main peak is probably obscured by the anatase strong peak accustomed to be located at the same $2 q$ value $(\sim 25)$. In case of $\mathrm{GO}$ addition at the ratios of 70 and $90 \%$, a marked decrease in crystallinity as well as sizes of the anatase structure is perceived via vanishing some bands (such as those of the facets (004) and (105)) and shifting others into lower theta values like the interlayer spacing of (101), where the rest suffers a marked decrease in intensities. This latter shift emphasizes the increase in the $d$ values proposing an expansion in the nanotubes lattice spacings and thus comprehends the successful incorporation between RG and TNT. This advocates the sensitivity of the latter planes when GO interacts with the $\mathrm{TiO}_{2}$ nanotubes. The $30 \mathrm{TNT}-70 \mathrm{GO}$ and $10 \mathrm{TNT}-90 \mathrm{GO}$ samples also revealed broad peaks at $2 \mathrm{q}=$ $14.8^{\circ}(200)$ ad $44.32^{\circ}$ (204) never seen in 50 TNT-50 GO ascribed to the titanate nanotube [15]. This highlights that the $\mathrm{GO}$ excess oxygen helps establishing the structure of the hydrogen titanate.

Transmission electron microscopy (TEM) and selected area electron diffraction (SAED) images seen for 10GO-90TNT as well as 50GO-50TNT catalysts are depicted in Fig. 2. The TEM picture seen for the former shows overlaying of the interconnected TNTs; of an average inner diameter of $25 \mathrm{~nm}$ and length equal $500 \mathrm{~nm}$, over the RG that composed of $\sim 5$ layers. The inset SAED rings certified the presence of (101) and (004) anatase planes covered by the (200) plane of the RG, which carefully matches the corresponding XRD profile. This estimates the intimate interaction between the anatase TNT and RG. The HRTEM inset image verifies the SAED results via exposing $0.352 \mathrm{~nm}$ and $0.19 \mathrm{~nm}$ lattice spacings in which the former agrees with either the (101) anatase plane or the (200) of the RG plane where the spacing of $0.19 \mathrm{~nm}$ verifies the (200) plane of titanate. This proves the presence of surface contacts between RG and TNT.

For the 50TNT-50GO sample, the nanotube structure was entirely damaged to display the evolution of an aggregated nanoparticles array of $7 \mathrm{~nm}$ dimension. Similarly, the HRTEM shows the presence of lattice 
spacings correspond to either (101) of anatase or (200) of RG at $0.352 \mathrm{~nm}$ beside the lattice spacing 0.19 $\mathrm{nm}$ consistent with the (200) plane of titanate. This manifests the contact of the intersected area between the two components. The SAED circles are perfectly correlated to the crystalline mixed phases of TNT and RG attained via the notification of the planes at (101), (440) and (200), respectively.

The FT-IR spectra measured for evaluating the variations in the functional groups following the hybrid interaction between titanates and graphene are seen in Fig. 3. Apparently, GO displays many absorption peaks comparable to oxygen-containing functional groups including 1750, 1642, 1394, 1261, 1067 and $3450 \mathrm{~cm}^{-1}$ assigned respectively to $\mathrm{C}=\mathrm{O}, \mathrm{C}=\mathrm{C}, \mathrm{C}-\mathrm{OH}, \mathrm{C}-\mathrm{O}, \mathrm{C}-\mathrm{O}-\mathrm{C}$ and $-\mathrm{OH}$ groups. On the other hand, the TNT shows a hydroxyl stretching vibrational band at $3466 \mathrm{~cm}^{-1}$ beside peaks at 1645, 1394, 1002, 797 and $508 \mathrm{~cm}^{-1}$ endorsed respectively to $\mathrm{Ti}-\mathrm{OH}$ stretching, $\mathrm{C}-\mathrm{OH}$ and $\mathrm{Ti}-\mathrm{O}-\mathrm{Ti}$ vibrations in the titanate structure $\left(1002-508 \mathrm{~cm}^{-1}\right)$. The spectra of the hybrid indicate the typical feature of the titanate spectrum except shifting the $508 \mathrm{~cm}^{-1}$ band of the $\left[\mathrm{TiO}_{6}\right]$ octahedron vibration into $488 \mathrm{~cm}^{-1}$ in TNT50-G050 and $472 \mathrm{~cm}^{-1}$ in TNT30-G070, configuring the TNT distortion. This reflects that the interaction takes place mainly on the latter octahedron via involving of the RG (Ti-O-C). Also, some GO oxygenated bands are disappeared (such as 1750, 1261 and $1067 \mathrm{~cm}^{-1}$ ) pointing out the importance of $\mathrm{C}=\mathrm{O}$ and $\mathrm{C}-\mathrm{O}$ moieties during the interaction with titanates. The stabilization of the $\mathrm{C}=\mathrm{C}$ bonds bring around the fruitful reduction of GO.

The UV-visible spectra of the synthesized samples are presented in Fig. 4A. Undeniably, the UV-visible spectrum of 50TNT-50GO exhibited a superior absorbance across the whole range including the visible region (400-800 nm) than the other samples. Enhancing the absorption edge to an extended long absorption for all GO incorporated TNT especially the latter sample suggests their intimate interaction. The optical band gaps anticipated using the Tauc relation indicate values comprised of 2.6, 2.75, 2.88 and 3.1 for 50TNT-50GO, 30TNT-70 GO, 10TNT-90 GO and TNT, respectively.

To examine the charge carrier's transfer as well as their recombination and separation, a photoluminescence emission was analyzed for all the samples. The fluorescence spectrum of 50TNT$50 \mathrm{GO}$ owns the lowest intensity followed by 30TNT-70GO and 10TNT-90GO where the TNT acquires the highest intensity (Fig. 4B). Hence, the GO incorporated TNT samples verified the low recombination rate to be in the order; 50TNT-50GO > 30TNT-70GO > 10TNT-90GO. The TNT sample shows a peak at about $475 \mathrm{~nm}$ ascribed to the surface oxygen vacancies from the $\mathrm{TiO}_{2}$ defects. Different emission peaks localized at $\sim 600 \mathrm{~nm}$ emitting photons in the visible range were shown for all GO incorporated TNT samples proposing the presence of defects in TNT. This observation has been ascribed to the presence of an impurity band prompted from the RG addition that helps the energy transfer from the RG to TNT or vice versa [16].

\section{Photoelectrochemical water splitting}

The PEC performance of the plain TNT and GO incorporated TNT samples stacked on FTO were examined to display their photocatalytic activities. The current density vs. potential $(\mathrm{J}-\mathrm{V})$ curves 
performed under replicated solar irradiation were evaluated in $1.0 \mathrm{M} \mathrm{KOH}$, as depicted in Fig. 5. The photoelectrochemical consequence of the 50TNT-50GO shown in Fig. 5a upon sweeping the potential cathodically, reveals a sharp rise in the current density comprised of $9.2 \mathrm{~mA} \mathrm{~cm}^{-2}$ and at an onset potential equal $0.2 \mathrm{~V}$ vs. RHE. On the other hand, the 30TNT-70GO and 10TNT-90GO samples showed smaller photocurrent densities, with comparable values at $4.0 \mathrm{~mA} / \mathrm{cm}^{2}$ and $3.7 \mathrm{~mA} / \mathrm{cm}^{2}$; parallel to onset potential of $0.385 \mathrm{~V}$ and $0.4 \mathrm{~V}$, respectively. However, the TNT photocathode shows an inferior photocurrent value $\left(0.3 \mathrm{~mA} \mathrm{~cm}{ }^{2}\right)$ following illumination of the solar emulator and rather perceived at higher potential equivalent to $0.43 \mathrm{~V}$ vs. RHE. Boosting the current density of the 50TNT-50GO sample; compared to other samples, that acquired at lower onset potential proposes extra effective charge separation and compilation than the other catalysts, as confirmed from the PL results. Also, the great negative shift of the onset potential of the former sample necessitates an intimate interaction between TNT and GO; as confirmed from IR and TEM results. This indicates that the photo-generated electrons in TNT conduction band are conveyed to the graphene oxide of lower work function [17].

Furthermore, the physicochemical stability while performing the PEC water splitting is evaluated via drawing the time-dependent current density at a constant bias equal 1.0 V against RHE (Fig. 5B). As exhibited in the Figure, the current densities of all samples are jumped to their maximum values following illumination and instantaneously decreased after light turning off, signifying their rapid photoelectric response power. The TNT50-G050 photocathode shows the highest photocurrent density (about 9.2 $\mathrm{mA} / \mathrm{cm}^{2}$ ) compared with the other photoanodes and after 6 repeated cycles it signifies a decline in the current density comprised of $7.9 \mathrm{~mA} / \mathrm{cm}^{2}$. This distinctly indicates that the TNT-GO heterojunction possesses superior borderline charge-transfer efficacy resulted from the exhibited considerable interaction between the two components. Exhibition of the rectangular shapes in the $\mathrm{J}$-t investigations reveal not only a decrease in the electron back recombination but also an effective reproducibility of the photo-anodic actions. To emphasize the facility of the charge transfer and to what extent the internal resistance can affect the capacity of the samples the impedance spectra of the samples were measured and shown in Fig. 5C. The semicircle diameter of the 50TNT-50GO photocatalyst was smaller in sequence than 30 TNT-70 GO, 10 TNT-90 GO and TNT ones, advocating higher heterojunction charge transfer as well as efficient electron/hole separation following the amalgamation with $\mathrm{GO}$.

Important factors such as surface texturing (pore radius, pore volume and surface area) properties are very important factors to affect the electrolyte absorbability and the amount of solar light absorbed. Table 1 shows the $S_{B E T}, V p$ and $r$ values, in which the surface area values were in the sequence of TNT > 10 TNT- $90 \mathrm{GO}>30$ TNT-70 GO > 50 TNT-50 GO whereas the pore volume data states that the 50 TNT-50 $\mathrm{GO}$ sample exhibits the highest value exploring higher electrolyte adsorption. Increasing the pore volume of the latter sample proposes the strong interaction between TNT and GO components, in which GO is deeply pushed inside the pore causing pore volume enlargement. This is highly ascertained via decreasing the pore diameter; to be the smallest, to elucidate the crowding of GO at the TNT pore mouth affecting its dimension. 
Figure 5D shows the Tafel plots of all the photocatalysts. The slope of 50TNT-50GO (40 mV dec-1) was much lower than those of 30 TNT-70 GO (73 mV dec $\left.{ }^{-1}\right)$ and 10 TNT-90 GO (71 mV dec $\left.{ }^{-1}\right)$ and comparable to that of $\mathrm{Pt} / \mathrm{C}\left(38 \mathrm{mV} \mathrm{dec}^{-1}\right)$. This reveals more promising catalytic kinetics on the former catalyst. This superior photocatalytic activity of the 50 TNT-50GO catalyst is ascribed to the synergism between TNT and GO besides the high electronic conductivity offered from the produced reduced graphene.

The lower value of 50TNT-50GO is indeed designs that the discharging mechanism (Tafel and/or Heyrovsky) is the principal route, realizing that the hydrogen evolution is the rate determining stage (combination reaction).

Volmer; $\mathrm{H}^{+}+\mathrm{e}-{ }^{\circledR} \mathrm{H}_{\mathrm{ad}}$

Heyrovsky; $\mathrm{H}_{\mathrm{ad}}+\mathrm{e}^{-}+\mathrm{H}^{+} \circledast \mathrm{H}_{2}$

This ascribes that 50TNT-50GO has a potentiality for electrons transmission thus enhances the hydrogen evolution densities that was in accord with diminishing the electrochemical resistance. However, in case of 30 TNT-70 GO and 10 TNT-90 GO, a Volmer reaction is counted as the rate limiting step owing to sticking the $\mathrm{H}_{\mathrm{ad}}$ more on their surfaces [18] thus promoting slow electrochemical desorption step and thus the slow kinetics. during performing the electrochemical reactions (Table 1).

Table 1: Surface properties of the studied photoelectrocatalysts

\begin{tabular}{|llll|}
\hline Material name & $\mathbf{S}_{\mathrm{BET}}$ surface area $\left(\mathrm{m}^{2} / \mathbf{g}\right)$ & Pore volume $\mathrm{Vp}\left(\mathrm{cm}^{3} / \mathbf{g}\right)$ & $\begin{array}{l}\text { Pore diameter- BJH } \\
\mathrm{r}(\mathrm{nm})\end{array}$ \\
\hline TNT & 240 & 1.35 & 19.5 \\
\hline $\mathbf{5 0}$ TNT-50 GO & 185 & 1.85 & 17.8 \\
\hline 30 TNT-70 GO & 201 & 1.41 & 18.5 \\
\hline 10 TNT- 90 GO & 220 & 1.38 & 19.2 \\
\hline
\end{tabular}

The photocatalysts quantum efficiencies were evaluated at $0.5 \mathrm{~V}$ vs. RHE from utilizing a monochromator with a power meter and photo-diode, assumed by the equation: IPCE\% $=1240 \mathrm{~J}_{\mathrm{ph}} / \mathrm{I}_{\text {inc }} \lambda \times 100 \%$; where $\mathrm{J}_{\mathrm{ph}}$ is the measured photocurrent density $\left(\mathrm{mA} / \mathrm{cm}^{2}\right), \mathrm{l}_{\text {inc }}$ is the incident light power intensity $\left(\mathrm{mW} / \mathrm{cm}^{2}\right)$ at the electrode surface where $\lambda$ is the wavelength $(\mathrm{nm})$ of the emitted light. The calculated IPCE values was maximized for the 50TNT-50GO photocatalyst giving a value of $45 \%$ at $400 \mathrm{~nm}$ that dropped off into $25 \%$ and $10 \%$ for 30TNT-70GO and 10TNT-90GO, respectively. Boosting the photocurrent of the former is likely caused by decreasing the band gap, enhancing the visible light absorption range, high charges separation and deep pore volume.

Constructively, our cost effective photocatalyst 50TNT-50GO has shown superior photoelectrocatalytic water splitting performances $\left(9.2 \mathrm{~mA} \mathrm{~cm}^{-2}\right)$ compared to others in literatures such as various black titania 
either produced via reduction by $\mathrm{CaH}_{2}\left(1.99 \mathrm{~mA} \mathrm{~cm}^{-2}\right)$ or $\mathrm{Mg}$ metal $\left(3.1 \mathrm{~mA} \mathrm{~cm}{ }^{-2}\right)$ [19-20]. It also exceeds those of the ternary structured $\mathrm{Ag} / \mathrm{TiO}_{2} / \mathrm{CNT}\left(0.9 \mathrm{~mA} \mathrm{~cm}{ }^{-2}\right), \mathrm{TiO}_{2} @ \mathrm{RG}\left(6.0 \mathrm{~mA} \mathrm{~cm}{ }^{-2}\right)$, reduced graphenegraphene oxide nanohybrid $\left(61.35 \mu \mathrm{A} / \mathrm{cm}^{2}\right)$ and controlled film of $\mathrm{TiO}_{2}$ nanotubes $\left(175 \mu \mathrm{A} \mathrm{cm}{ }^{-2}\right)$ [21-24] all performed in the same electrolyte.

\section{Conclusion}

The nanohybrid 50TNT-50G0 synthesized by microwave irradiation approach verified its ability to accomplish high performance PEC water splitting under solar illumination with exhibiting high current density $\left(9.2 \mathrm{~mA} \mathrm{~cm}^{-2}\right)$ at low bias $(0.2 \mathrm{~V})$ and small Tafel slope values $\left(40 \mathrm{mV} \mathrm{dec}^{-1}\right)$. The heterojunction photoanode 50TNT-50GO of nanospherical array facilitates chargers transfer via the constructed interface formed between TNT and RG, and thus improved the visible light absorptivity. Lowering the energy gap (2.6 eV) and charges separation efficacy as well as their transport feasibility, beside the high quantum yield and pore volume are all share in attaining efficient hydrogen production from water via solar energy conversion.

\section{Declarations}

\section{Acknowledgements}

Taif University Researchers Supporting Project number (TURSP-2020/05), Taif University, Taif, Saudi Arabia

\section{Data Availability' statement}

The authors confirm that the data supporting the findings of this study are available within the article. Raw data and Derived data supporting the findings of this study are available from the corresponding author [Mohamed Mokhtar] on request.

\section{References}

1. M. El-Shahat, M.M. Mohamed, M.M. Rashad, M. A. Mousa "Single and ternary nanocomposite electrodes of $\mathrm{Mn}_{3} \mathrm{O}_{4} / \mathrm{TiO}_{2} / \mathrm{rGO}$ for supercapacitors". J. Solid State Electr (2020). https://doi.org/10.1007/s10008-020-04837-2

2. M.M. Mohamed, W.A. Bayoumy, T.Y.M. El-Ashkar, M.E. Goher, M. H. Abdo "Graphene oxide dispersed in $\mathrm{N}-\mathrm{TiO}_{2}$ nanoplatelets and their implication in wastewater remediation under visible light illumination: Photoelectrocatalytic and photocatalytic properties". J. Environ. Chem. Eng. 7, 102884102889 (2019). https://doi.org/10.1016/j.jece.2019.102884

3. M.M. Mohamed, T.Y.M. El-Ashkar, W.A. Bayoumy, M.E. Goher, M. H. Abdo "Optimization of a$\mathrm{Fe}_{2} \mathrm{O}_{3} @ \mathrm{Fe}_{3} \mathrm{O}_{4}$ Incorporated $\mathrm{N}-\mathrm{TiO}_{2}$ as Super Effective Photocatalysts Under Visible Light Irradiation". Appl. Surf. Sci. 412, 668-682 (2017). https://doi.org/10.1016/j.apsusc.2017.03.200 


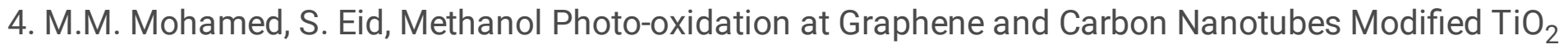
Nanosheets Electrocatalysts. J. Photochem. Photobiol. A. 338, 37-48 (2017). https://doi.org/10.1016/j.jphotochem.2017.02.005

5. S. Al-Mayman, M.S. Al-Johani, M. Mohamed, Y. Al-Zeghayer, S.M. Ramay, A. Al-Awadi, M. Soliman " $\mathrm{TiO}_{2}-\mathrm{ZnO}$ Photocatalysts synthesized by Sol-Gel Auto-Ignition Technique for Hydrogen Production". Int. J. Hydrog. Energy 42, 5016-5025 (2017). https://doi.org/10.1016/j.ijhydene.2016.11.149

6. T. Okato, T. Sakano, M. Obara, "Suppression of photocatalytic efciency in highly N-doped anatase flms". Phys. Rev. B 72, 115124-115130 (2005). DOI:10.1103/PhysRevB.72.115124

7. H. Dang, X. Dong, Y. Dong, J. Huang, Facile and green synthesis of titanate nanotube/graphene nanocomposites for photocatalytic $\mathrm{H} 2$ generation from water. Int. J. Hydrog. Energy 38, 9178-9182 (2013). https://doi.org/10.1016/j.ijhydene.2013.05.061

8. (a) L. Shen, X. Zhang, H. Li, C. Yuan, G. Cao" Design and Tailoring of a Three-Dimensional $\mathrm{TiO}_{2}-$ Graphene-Carbon Nanotube Nanocomposite for Fast Lithium Storage" J. Phys. Chem. Lett., 2 (2011) 3096 - 3010, https://doi.org/10.1021/jz201456p; (b) P. Song, X. Zhang, M. Sun, X. Cui and Y. Lin "Graphene oxide modified TiO2nanotube arrays: enhanced visible light photoelectrochemical properties" Nanoscale, 4 (2012) 1800, https://doi.org/10.1039/C2NR11938B

9. P. Kumar, R. Boukherroub, and K. Shankar "Sunlight-driven water-splitting using two dimensional carbon based semiconductors". J. Mater. Chem. A 6, 12876-12931 (2018). https://doi.org/10.1039/C8TA02061B

10. D.V. Bavykin, J.M. Friedrich, F. C. Walsh "Protonated Titanates and $\mathrm{TiO}_{2}$ Nanostructured Materials: Synthesis, Properties, and Applications". Adv. Mater. 18, 2807-2824 (2006). https://doi.org/10.1002/adma.200502696

11. T. Lindgren, J.M. Mwabora, E. Avendano, J. Jonsson, A. Hoel, C.-G. Granqvist, Lindquist "Photoelectrochemical and Optical Properties of Nitrogen Doped Titanium Dioxide Films Prepared by Reactive DC Magnetron Sputtering". J. Phys. Chem. B 107, 5709-5716 (2003). https://doi.org/10.1021/jp027345j S.-E.

12. L.K. Preethi, R.P. Antony, T. Mathews, S.C.J. Loo, L.H. Wong, S. Dash, Tyagi "Nitrogen doped anataserutile heterostructured nanotubes for enhanced photocatalytic hydrogen production: Promising structure for sustainable fuel production". Int. J. Hydrog. Energy 41, 5865-5877 (2016). https://doi.org/10.1016/j.jijhydene.2016.02.125. A. K.

13. K.K. Patra, C.S. Gopinath, "Bimetallic and Plasmonic $\mathrm{Ag}-\mathrm{Au}$ on $\mathrm{TiO}_{2}$ for Solar Water Splitting: An Active Nanocomposite for Entire Visible-Light-Region Absorption". ChemCatChem 8 (2016) 32943311, DOI: 10.1002/cctc.201600937;Y. Yang, J. Xiao, H. Wei, L. Zhu, D. Li, Y. Luo, H. Wu, Q. Meng "An all-carbon counter electrode for highly efficient hole-conductor-free organo-metal perovskite solar cells" RSC Adv., 4 (2014) 52825-52830

14. L.L. Lai, W. Wen, J.-M. Wu, Room-Temperature Hydrolysis of Potassium Titanyl Oxalate and WaterAssisted Crystallization for $\mathrm{TiO}_{2}$ with High Photocatalytic Activity. Chemistry Select 2, 5025-5031 (2017). https://doi.org/10.1002/slct.201700372 
15. K. Sivaranjani, S. RajaAmbal, T. Das, K. Roy, S. Bhattacharyya, C. S. Gopinath "Disordered Mesoporous $\mathrm{TiO}_{2}-\mathrm{xNx}+$ Nano-Au: An Electronically Integrated Nanocomposite for Solar $\mathrm{H}_{2}$ Generation". Chem.Cat.Chem 6, 522-530 (2014). https://doi.org/10.1002/cctc.201300715

16. M.A. Reshchikov, H. Morkoç, Luminescence properties of defects in GaN. J. Appl. Phys. 8, 061301061395 (2005). https://doi.org/10.1063/1.1868059

17. M.M. Mohamed, T.M. Salama, M. Morsy, R.M. Abou-Shahba, S. H. Mohamed "Facile Strategy of Synthesizing a- $\mathrm{MoO}_{3-\mathrm{x}}$ Nanorods Boosted as Traced by $1 \%$ Graphene Oxide: Efficient Visible Light Photocatalysis and Gas Sensing Applications", Sens. Actuators B Chem. 299, 126960-112969 (2019). https://doi.org/10.1016/j.snb.2019.126960

18. G. Zhu, H. Yin, C. Yang, H. Cui, Z. Wang, J. Xu, T. Lin, F. Huang, Black Titania for Superior Photocatalytic Hydrogen Production and Photoelectrochemical Water Splitting. " Chem.Cat.Chem 7, 2614-2619 (2015). DOI:10.1002/cctc.201500488

19. M.M. Mohamed, T.M. Salama, M.A. Hegazy, R.M. Abou Shahb, S.H. Mohamed "Synthesis of hexagonal $\mathrm{WO}_{3}$ nanocrystals with various morphologies and their enhanced electrocatalytic activities toward hydrogen evolution". Int. J. Hydrogen Energy 44(10), 4724-4736 (2019)

20. J. Xu, Z. Tian, G. Yin, T. Lin, F. Huang, “Controllable reduced black titania with enhanced photoelectrochemical water splitting performance”.. Dalton Trans. 46, 1047-1052 (2017). https://doi.org/10.1039/C6DT04060H

21. D. Chaudhary, S. Singh, V.D. Vankar, N. Khare, A ternary $\mathrm{Ag} / \mathrm{TiO}_{2} / \mathrm{CNT}$ photoanode for efficient photoelectrochemical water splitting under visible light irradiation. Int. J. Hydrogen Energy 42, 78267835 (2017). DOI:10.1016/j.jjhydene.2016.12.036

22. S.T. Kochuveedu, H. Kim, M.J. Jeong, F.M. Mota, J.H. Park, D. H. Kim “Plasmon-Sensitized Graphene/ $\mathrm{TiO}_{2}$ Inverse Opal Nanostructures with Enhanced Charge Collection Efficiency for Water Splitting Ramireddy Boppella". ACS Appl. Mater. Interfaces 9, 7075-7083 (2017). https://doi.org/10.1021/acsami.6b14618

23. B. A. Aragaw "Reduced graphene oxideintercalated graphene oxide nanohybrid for enhanced photoelectrochemical water reduction" Journal of Nanostructure Chem. 10 (2020) 9-18, DOI:10.1007/s40097-019-00324-x

24. M. Zelny, S. Kment, R. Ctvrtlik, S. Pausova, H. Kmentova, J. Tomastik, Z. Hubicka, Y. Rambabu, J. Krysa, A. Naldoni, P. Schmuki, R. Zboril " $\mathrm{TiO}_{2}$ Nanotubes on Transparent Substrates: Control of Film Microstructure and Photoelectrochemical Water Splitting Performance". Catalysts 8, 25-34 (2018). https://doi.org/10.3390/catal8010025

\section{Figures}




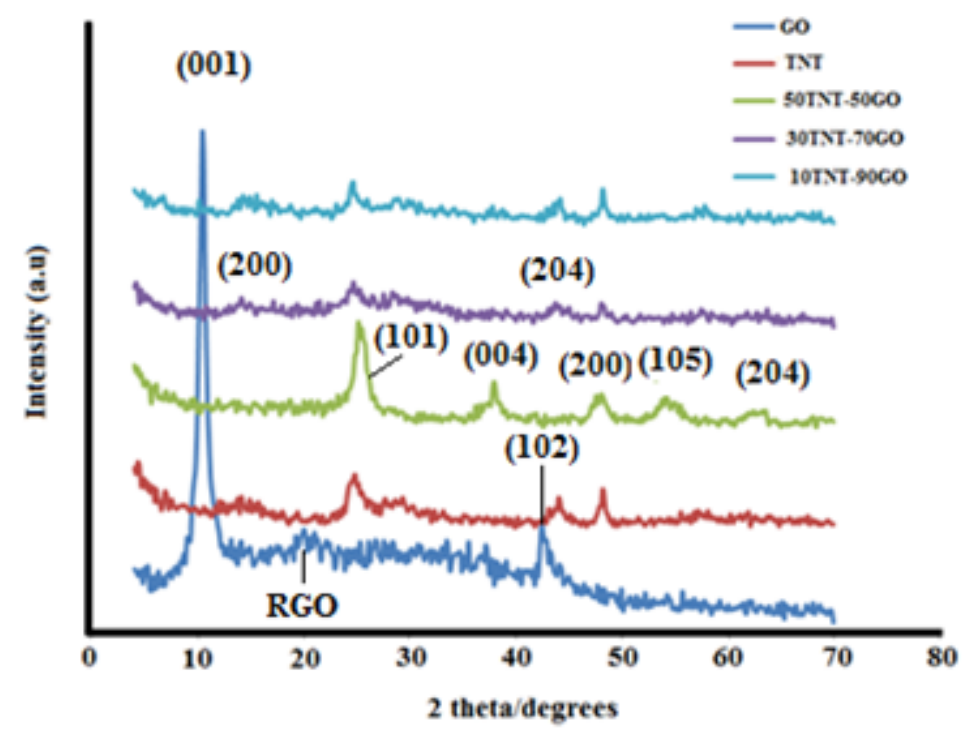

Figure 1

XRD of the as synthesized samples 

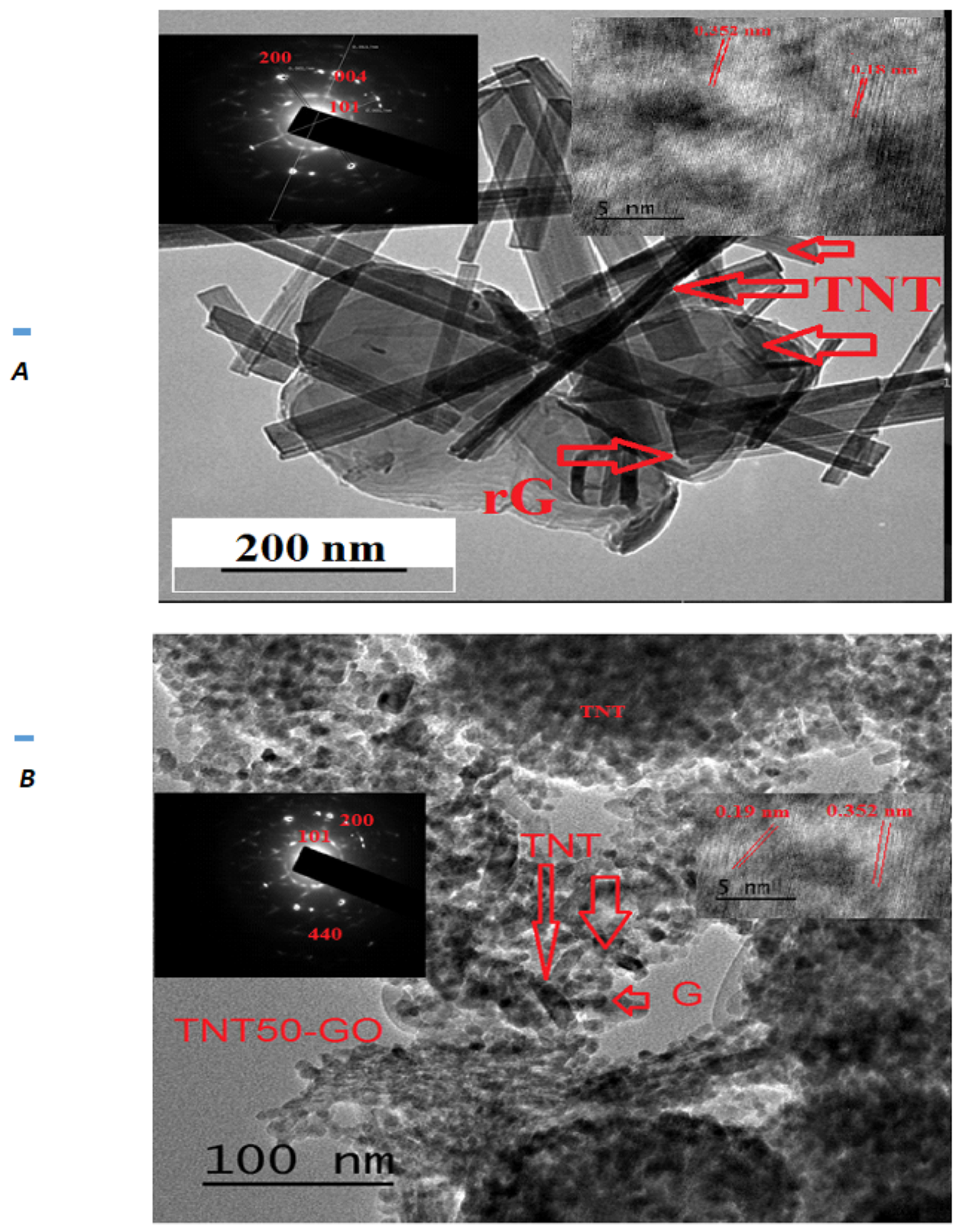

Figure 2

TEM, and inset images of both HRTEM and SAED of A) 10 GO-90 TNT and B) 50 GO-50 TNT samples. 


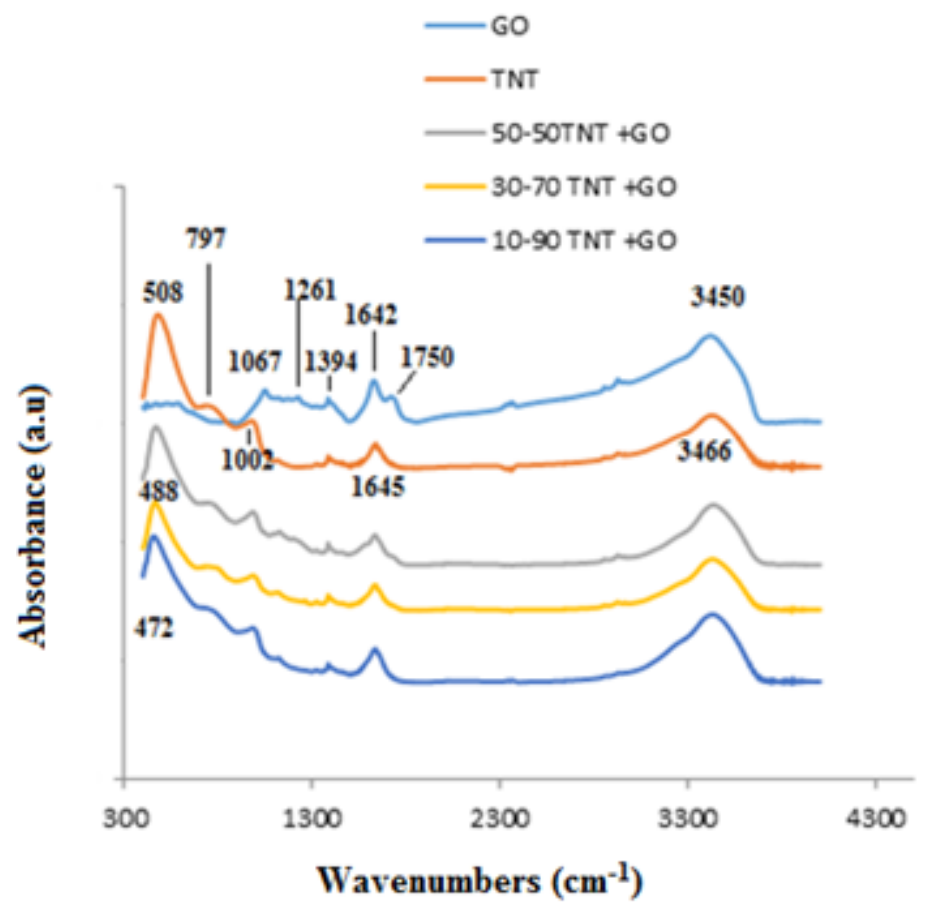

Figure 3

FTIR spectra of the as synthesized samples
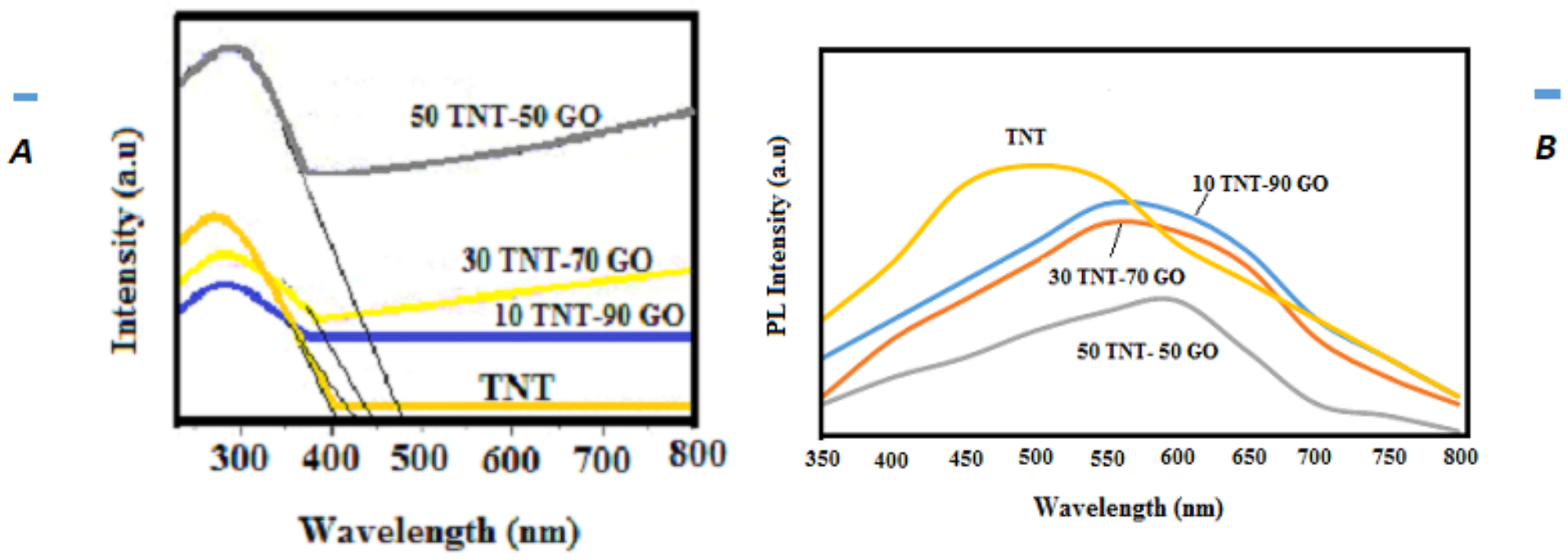

Figure 4

UV-Vis diffuse reflectance $(A)$ and the PL emission spectra (B) of the synthesized samples 

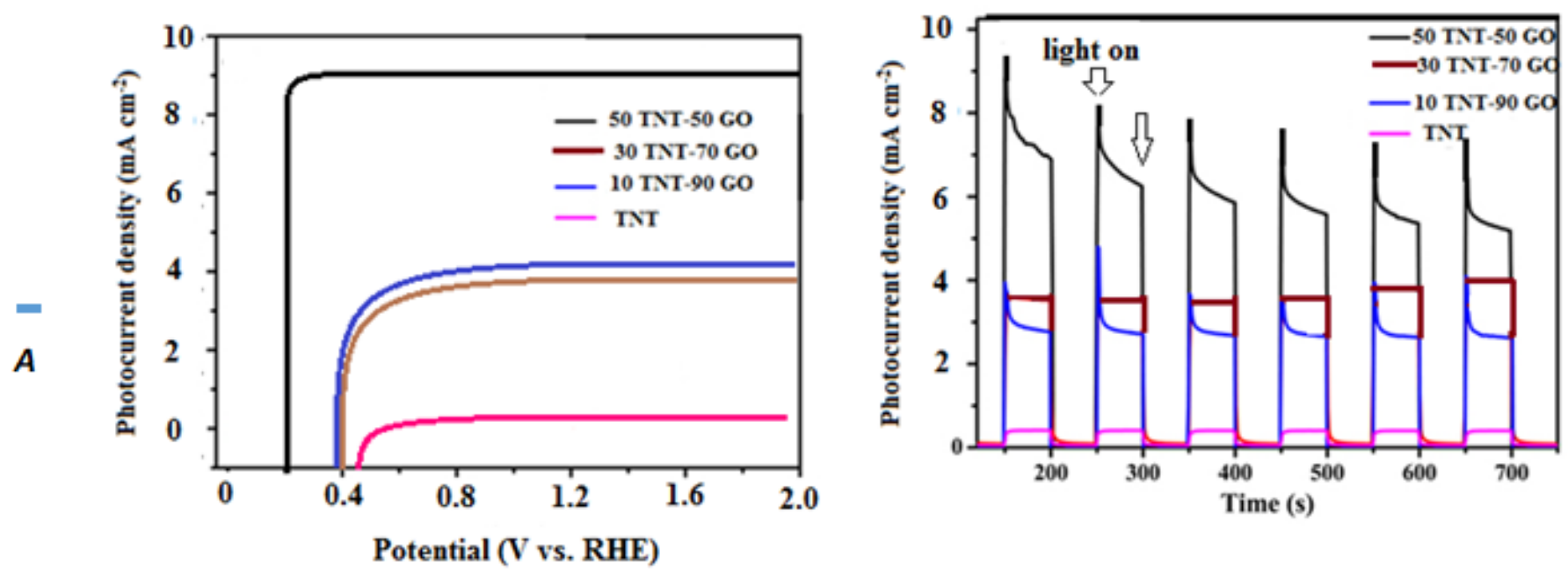

B
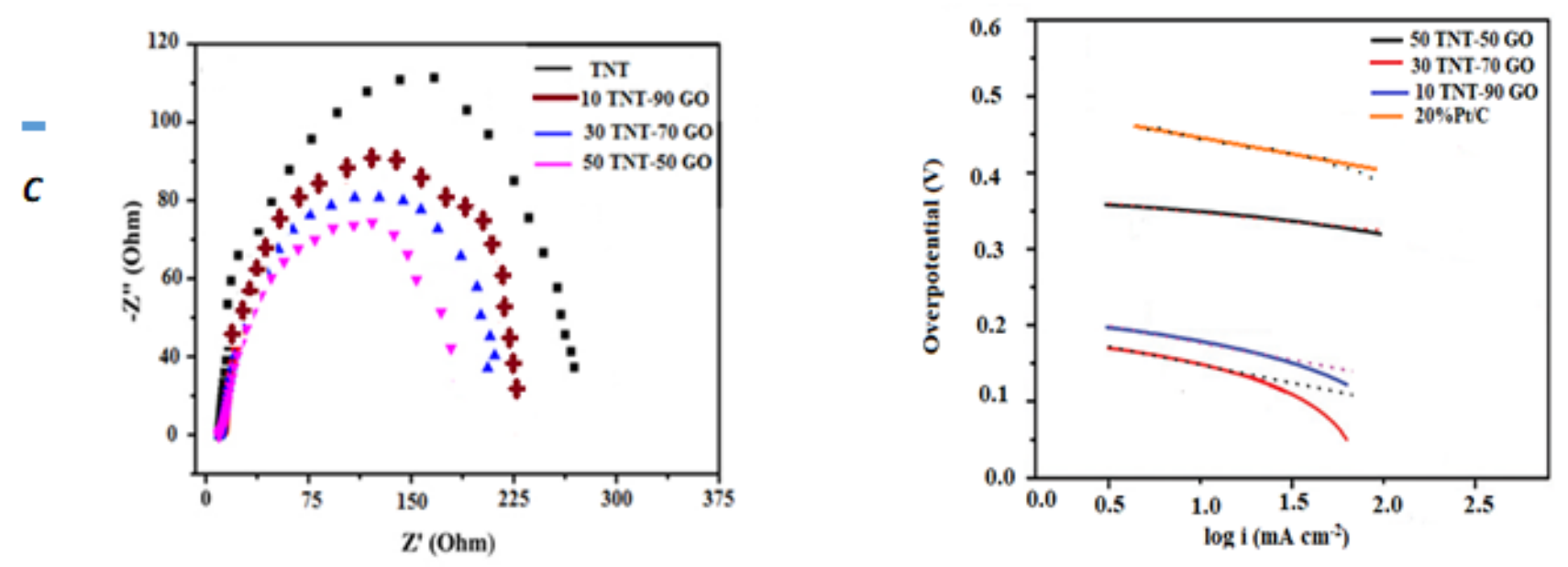

Figure 5

The HER performance of $x$ TNT-y GO photocatalysts. A) LSV curves at a scan rate of $10 \mathrm{mV} \mathrm{s}-1$ (b) timedependent photocurrent density at repeated on/off cycles under simulated sunlight illumination. C) Els and (D) Tafel plots. 